\title{
Exploring Cognitive Aspects of Competence in Sign Language Inter- preting of Dialogues: First Impressions
}

\begin{abstract}
Sign language interpreting of dialogues shares many features with the interpreting of dialogues between non-signed languages. We argue that from a cognitive perspective in dialogue interpreting, despite some differences between the two types of interpreting, sign language interpreters use many of the same processes and handle similar challenges as interpreters between non-signed languages. We report on a first exploration of process differences in sign language interpreting between three novice and three experienced Swedish Sign Language interpreters. The informants all interpreted the same dialogue and made a retrospection of their interpreting immediately after the task. Retrospections were analyzed using tools for identifying reported processing problems, instances of monitoring, and strategy use (see Ivanova 1999). Furthermore, the interpreting products (both into Swedish Sign Language and into Swedish) and their differences were qualitatively analyzed. The results indicate that there are differences between the two groups, both in terms of the retrospective reports and in terms of the interpreting product. As expected, monitoring seems to be a factor determined by experience. The experienced interpreters seemed to have more efficient ways of handling turn taking and the internalization of new vocabulary. The study also concludes that to use instruments devised for simultaneous conference interpreting (Ivanova 1999; Tiselius 2013), the instruments need to be adapted to the dialogue setting, even though in the case of sign language interpreting the simultaneous interpreting technique is used even in dialogue interpreting.
\end{abstract}

\section{Keywords}

interpreting; dialogue interpreting; sign language interpreting; cognitive processes; retrospection; experience

\section{Introduction}

Sign language interpreting (SLI) in dialogue settings has much in common with dialogue interpreting between non-signed languages (NSLIs). The SL interpreter in a medical consultation, for instance, must monitor participants' contributions to the dialogue, ensure comprehension, handle turn taking, cope with possible asymmetrical levels of their own working languages, and deal with ethical issues of power, in the same way that the dialogue NSL interpreter does. Three major differences can be identified: 1) SLI is bi-modal (unless it concerns interpreting between two sign languages, a field that will not be dealt with in this article), with the interpreter working between the visual signed language and the oral spoken language; 2) SL interpreters almost always work in simultaneous mode, even when interpreting dialogues; and 3) SL interpreters mostly work for deaf clients of the same national background as the hearing clients. SLI research covers a wide range of topics and has grown exponentially over the past two decades (Napier 2015). Research has focused on, for instance, the interpreter's role (Tate/Turner 2002; Conrad/Stegenga 2005; Schwenke et al. 2014), various aspects of the multi-modality of the task at hand (Nicodemus/Emmorey 2013), quality (Wehrmeyer 2015) and training (Llewellyn-Jones 2013). Studies cited here are only examples from the different fields.

\footnotetext{
* Elisabet Tiselius

Stockholm University/Western Norway University of Applied Sciences

Institute for Interpreting and Translation Studies

10691 Stockholm

elisabet.tiselius@su.se
} 
Similar to research into NSL, SLI research has not focused on cognitive aspects of dialogue interpreting. Cognitive research in SLI has focused on simultaneous interpreting of monologues, such as working memory (van Dijk et al. 2012), lag (Cokely 1986), and coping strategies (Napier 2002), but as far as we have been able to establish not on cognitive aspects of simultaneous interpreting of dialogues. Furthermore, few parallels have been drawn between interpreting between a signed and a non-signed language, on the one hand, and interpreting between two nonsigned languages on the other hand; an exemption is Swabey et al. (2016) who compared errors and omissions as evidence of cognitive load in French, German, Japanese and ASL. For a detailed and comprehensive comparison between dialogue (community) SLI and NSLI both in terms of practice and research see Grbić/Pöllabauer (2006).

Tiselius (2013) investigated cognitive processes in simultaneous interpreting between spoken languages, and Englund Dimitrova and Tiselius (2016) have initiated a study on competence and cognition in NSL dialogue interpreting. In the case of SLI, just as in NSLI, there is little systematized evidence in dialogue interpreting regarding cognitive characteristics of interpreters with different amounts of experience and varying competence levels, an area that has been thoroughly studied in conference interpreting, both in simultaneous and consecutive mode (for SLI, see above; for NSLI, see Köpke/Nespoulous 2006; Timarova 2012; Tiselius 2013). One can assume that the cognitive effort and possible cognitive load of dialogue interpreting is similar to, although not the same as, conference interpreting. This is especially the case in SLI, where the interpreting technique is simultaneous and where the interpreter therefore work (just as in simultaneous between spoken languages) in both channels (listening or producing), which is not the case in dialogue interpreting between spoken languages. For conference interpreting, research shows that interpreting experience has an impact on the interpreting output (Tiselius 2013) as well as on the interpreter's strategies (Ivanova 1999; Vik-Tuovinen 2006; Tiselius 2013; Hoza 2016) and cognitive resources (Köpke/Nespolous 2006; Liu 2009; Timarova 2012). It is likely that the same thing is true for sign language dialogue interpreting.

The aim of the study reported in this article was to compare the performance of experienced and inexperienced Swedish Sign Language interpreters in an interpreted dialogue from a process perspective. A secondary aim was also to test whether methods previously used to investigate the interpreting process in simultaneous conference interpreting were applicable to SL interpreting in a dialogue setting. There were two main research questions:

1. Are there reported or observed differences in the interpreting process between experienced and inexperienced SL interpreters when interpreting a dialogue?

2. Are the methods used for investigating the interpreting process between spoken languages in monologue simultaneous mode also applicable to SL interpreting in dialogue simultaneous mode?

\section{Background}

Dialogue SL interpreting is both similar and different to spoken dialogue interpreting. Englund Dimitrova and Tiselius (2016) define community interpreting for spoken languages as a form of dialogue interpreting. They set a list of characteristics for that type of community interpreting, defining it as when the interpreters interpret dialogues "in the consecutive mode for both parties in a given encounter between majority- and minority-language speakers, working alternatingly into both languages" (2016: 196). SL interpreters, on the other hand, rarely work in the consecutive mode, not even in a dialogue, as the two languages are produced in different modalities, and simultaneous interpreting into either of the languages can be performed while the speakers speak. Despite this difference in the main technique when interpreting dialogues, we would argue that dialogue SLI requires the same skills as dialogue NSLI and that SLI in dialogue interpreting must handle many of the same challenges as interpreters of non-signed languages. There are, of course, 
challenges and skills (other than bimodality) that are different as well, especially from an ethical and sociological perspective. Examples of such differences are the positioning of the interpreter (the SL interpreter has to be seen by the deaf client at all times) or the minority language group interpreted for (deaf on the one hand and foreigners or migrants on the other). These aspects will not be focused on here, as the main objective of this study concerns the cognitive aspects of the interpreting process.

As suggested by Englund Dimitrova and Tiselius's overview of the theoretical and empirical research literature on both SL and NSL dialogue interpreting (Englund Dimitrova/Tiselius 2016; see also Kaczmarek 2010; Bontempo/Napier 2014), dialogue interpreters need to master at least the following skills to fulfil their interpreting task:

- Advanced language knowledge for both comprehending and producing utterances in two languages (Frishberg 1990: 25; Hale 2007: 22-23 and 177; Corsellis 2008: 24; Skaaden/ Wadensjö 2014: 20).

- Both general background knowledge of (at least) two societies and cultures and specific domain knowledge within, e.g., the medical field (Frishberg 1990: 48-49; Hale 2007: 177; Corsellis 2008: 25; Corsellis/Vanden Bosch 2014: 69).

- Interpreting: This is an elusive competence that seems to comprise a range of sub-competences. The sub-competences of the interpreting skill consist of, but are not limited to, listening/perception, comprehension, memory, public speaking, non-verbal communication, transfer (into two languages), managing interaction (turn taking), managing attentional capacity, and monitoring production and detecting mistranslations or misunderstandings (Frishberg 1990: 30; Englund Dimitrova 1991, 1997; Roy 1993; Wadensjö 1998; Hale 2007: 177; Corsellis 2008: 25).

- Professional self-concept: This is described by Andres (2011: 86) as the interpreter's professional understanding of his/her own activity and responsibility towards the other stakeholders in the interpreting situation, and by Hale (2007: 177) as "the ability to assess when it is necessary to intervene and how to do it; the ability to control and coordinate the interpreted situation”. Muñoz Martín (2014) defines it as a concept of translation expertise and says that it consists of self-awareness, situation awareness, and self-efficacy. Interpreting ethics and management skills are other parts of the professional self-concept.

Though there are of course other sources, such as teaching manuals, that also discuss what skills a dialogue interpreter requires, we believe the above list is comprehensive.

Examples of cognitive challenges that interpreters share in dialogue interpreting, regardless of the languages involved, include monitoring the participants' contributions to the dialogue, ensuring comprehension, handling turn taking, and dealing with asymmetrical levels of language knowledge in the two working languages. When it comes to language knowledge and interpreting, the International Association of Conference Interpreters (AIIC) labels L1 as the 'A' language and the native-like L2 as the 'B' language, which the interpreter has a perfect command of and into which she or he works from one or more of her or his other languages. ${ }^{1}$ Following AIIC's definition, the dialogue interpreter's two languages should thus not be asymmetrical, as the interpreter should have a perfect command of the B language as well. However, most dialogue interpreters for both spoken and signed languages learn their L2 as adults, either as part of formal training (often the case for SL dialogue interpreters) or due to migration (often the case for dialogue interpreters between spoken languages), so that their language proficiency does not reach the levels of those who have learned the L2 continuously from childhood (Hyltenstam 2016).

1 https://aiic.net/page/4004/working-languages/lang/1 (accessed August 15, 2017). 
Although many dialogue interpreters of course have an advanced, native-like mastery of the L2, many others struggle with asymmetrical language knowledge.

Many models have been produced to map different types of interpreting, and SLI is no exception (e.g., Ingram 1978; Cokely 1992; Colonomos 1997). But as Wilcox and Schaeffer (2005) also point out, many early models overlooked the communicative and managerial aspect of interpreting. These early models had the interpreter as the main focus, and the environment and other participants, if at all present, were only props. Substantial research has now shown that the interpreter of dialogues has an important role in managing the conversation (see Frishberg 1990; Englund Dimitrova 1991, 1997; Roy 1993; Wadensjö 1998). In the overview of processes in community interpreting, Englund Dimitrova and Tiselius (2016) argue that the fundamental conditions of community interpreting (i.e., three-party dialogue and immediate feedback) impact the process requirements as it puts cognitive load on monitoring, co-ordination, and ethical awareness. These conditions are similar for SLI and NSLI, meaning that the particular conditions and differences in cognitive demand compared to simultaneous conference interpreting could, for instance, be related to handling turn taking and monitoring both the interpreter's and the other participants' production.

The concept of monitoring is regularly used in interpreting studies, yet rarely defined (see Gerver 1971; Moser 1978; Gile 1985; Setton 1999). Monitoring should, in our definition, be understood as the cognitive act of controlling the whole interpreting process, including, but not restricted to, the primary participants' perception, comprehension, production, and turn taking. It is linked to Levelt's (1989) perceptual loop theory of self-monitoring of speech in which the speaker constantly monitors his/her output, but where interpreters monitor not only their own spoken output but also the participants' output, understanding, and interaction. In this respect, such monitoring seems closely related to the action-monitoring system identified in cognitive and social neuroscience as a system "that assesses ongoing actions and detects errors" and that is "fundamental for adapting and optimizing behavior" (Bonini et al. 2014: 888). In the case of the dialogue interpreter, such ongoing actions would be those taken to ensure the best possible understanding and communication between the parties. Monitoring in this context should not be understood as Toury's (1995) monitor model of product and quality monitoring for translators, whereby the translation product is constantly (and partly unconsciously) monitored against a certain acceptable quality level.

From an expertise perspective, the monitoring skill can be assumed to be one of the variables that will change with time, practice, and experience (Englund Dimitrova/Tiselius 2016).

\section{Material and method}

The material in this study was elicited from six SL-interpreted events. The events were not authentic but performed as a semi-scripted role-play of a job interview. The manuscript of the roleplay was also performed with another SL interpreter and recorded before the actual data collection to create a cue for retrospection.

\subsection{Role-players}

The interpreted event was enacted with two female role-players: a deaf woman playing a job seeker, and a hearing, non-signing woman playing a guidance counselor. The event was semi-scripted, meaning that the role-players received a preparation sheet that covered the aim of the meeting, the required terminology, and certain difficulties they were expected to create (disrespect of turn taking, emotions such as anger and disappointment, etc.), but they were free to improvise their own dialogue depending also on the interpreting. The interpreters did not have access to the same preparation sheet as the role-players, but were offered some preparation just as for a real event (see below). 
At the same occasion as the recordings, but before the actual research recordings for the study were made, the role-play was performed with another, experienced SL interpreter in order to create a version for cueing the retrospection. As SLI is simultaneous even during a dialogue, this was made possible with the interpreter being outside the camera angle, and after the event, the interpreter's voice was edited away from the file. This resulted in a file that could give the participants a retrospection cue without the interpreter (i.e., themselves) being present. Arguably, as the development of the dialogue depends on the interpreter, this version was not the exact same as the one they interpreted, but they were similar enough to create a functioning cue.

Our reasons for choosing the data elicitation material that we used were the following: First, it is of course challenging to create a role-play that is natural enough to reflect a real interpreted event yet similar enough to create a comparable data set. In this case, we chose to create a preparation sheet with the different stages of the interview (greetings, presentation of the problem, discussion of the problem, possible solutions, and farewells), terminology (terms that should absolutely be used), and interpreting challenges (emotions, long utterances, and disrespect of turn-taking). Second, natural data was not appropriate in this case, as we suspected that the dialogue would vary too much between the different events. With a fully scripted role-play, conversely, the role-players risked reading instead of acting, thereby not creating a natural enough event for the interpreters; this would make it difficult to compare, for instance, the interpreters' strategies or processing problems. In order to compare the interpreted events and give the interpreters a cue for retrospection, however, the event does not necessarily need to be exactly the same: for instance, in order to compare how the interpreters dealt with disrespect of turn taking, we needed a similar disrespect of turn taking that was more or less at the same passage of the interpreted event, but we did not need an exact copy.

\subsection{Interpreter participants}

Three experienced interpreters were recruited through an interpreting agency to participate in this study. Two of the experienced interpreters had Swedish Sign Language as their L1, being born and raised in a deaf family, and having learned Swedish as an early L2. All three of the experienced interpreters had at least ten years of interpreting experience and interpreting training from Swedish folk high schools. ${ }^{2}$

The three inexperienced interpreters were students in the last term of the Swedish Sign Language interpreting BA program at Stockholm University. One of the participants had Swedish Sign Language as L1 and spoken Swedish as L2. All the participants received preparation materials, just as one can expect for an actual assignment, one week in advance, although two of the students later admitted they had not looked at it. As both the Swedish deaf and the Swedish Sign Language communities are small, all the participants have been given female names in order to keep their anonymity.

The fact that three of the participants most likely had a deeper knowledge of Swedish Sign Language than the other participants, as that language was their L1, may of course skew the results, and those participants were perhaps not struggling with asymmetrical language knowledge. However, asymmetrical language knowledge is not the only factor impacting the cognitive load of dialogue SLI; therefore, we believed that the sample would still yield valuable results.

\subsection{Research design}

The recordings were done at Stockholm University in a meeting room. All the interpreters knew beforehand that the interpreted event was a role-play and not an authentic situation. However, we believe that the surroundings and the role-players were perceived as authentic, since one of

2 The Swedish folk high schools are state-funded, independent centers for adult education and are different from high schools and universities in regard to both curricula and exams. 
the experienced interpreters commented on the fact that she had not understood that the guidance counselor was an actor but thought she was an actual guidance counselor acting in this role-play, and that the event was very similar to events she had interpreted at the public employment service in Sweden. It was important to us that the interpreted event, although a role-play, was perceived as authentic, allowing the interpreters to fully go into their role.

Two cameras were used to make sure all participants were seen on the recordings. All recordings were made on the same day. Immediately after interpreting the event, the interpreters did a retrospection cued with the recording prepared before the event without interpreting, as described above. The retrospections were recorded with both audio and video in order to catch supporting or explaining signs, as many interpreters use supporting signs when they speak. Students in the BA program of SLI at the Institute for Interpreting and Translation Studies at Stockholm University who collected material for their BA theses were trained to conduct retrospections with the informants. They were present in the room while the interpreter did the retrospection, sitting slightly behind them. After the retrospection, they asked follow-up questions.

The analysis was made on both the retrospections and the interpreting acts. Retrospections were coded for indications of processing problems, strategy use, and instances of monitoring following Ivanova's categories (for a thorough presentation of Ivanova's categories and how they are used in interpreting, see Ivanova 1999; Tiselius 2013; Englund Dimitrova/Tiselius 2014). In short, the analysis method is based on the following, the interpreter will give a recall of the interpreted event. The recall can be cued by a manuscript, the recording of the performance of the interpreter in question, or, as in our case, a model recording. The different issues that the interpreter raises in the retrospection is then categorized depending on the type of issue. If the interpreter recalls not understanding a certain concept, for instance, that would be coded as a processing problem.

The interpreting acts were analyzed and coded for indications of challenges with regard to turn taking and monitoring and of differences between the individual interpreters and the two interpreter groups. Instances when an interpreter had difficulties keeping the turn, for instance, would be analyzed and compared to similar cases for the other interpreters.

\section{Results}

This section will first report on the results from the participants' retrospections and then on the analysis of the interpreting acts. The analysis of the interpreting acts consists of both impressions from the participants as well as data from the interpretings.

\subsection{Length of interpreted events and retrospections}

The length of the interpreted events for the experienced interpreters varied between 16 and 22 minutes. It should be stressed, though, that this difference was not due to interpreting trouble but rather to the fact that some issues in the job-seeking process were emphasized more during one of the role-plays. As explained above, we did not judge these differences to be hindering comparisons. The events that were interpreted by the inexperienced interpreters lasted almost exactly 20 minutes for all three of them. The length of the event used for retrospection was 14:49, and the retrospections lasted between 17 and 23 minutes for the experienced interpreters and between 19 and 23 minutes for the inexperienced interpreters.

\subsection{Retrospections}

Retrospections were very different in nature as compared to earlier experiences when used after interpreting tasks in simultaneous conference interpreting (Tiselius 2013). It was clear that new categories had to be added to Ivanova's (1999) categories on monitoring. At least in this limited trial, the categories on processing problems seem to reflect well the reported processing problems in SL dialogue interpreting. When it comes to monitoring, however, Ivanova's categories 
unsurprisingly do not reflect any aspects of handling turn taking as they were developed from a material of simultaneous interpretings from monologues. Several of the comments concerned the handling of turn taking, such as "sometimes she [the deaf person] interrupts the hearing party, because she has gotten some of the information from the interpreter, and then it becomes impossible for me [the interpreter] to add the rest of the information". Another aspect that had to be added to the categories was conveying participants' ${ }^{6}$ mood. As described above, the role-players were asked to express anger and disappointment, and this was also something that the participants in this study commented more on, such as "I felt this [i.e., conveying disappointment] could be difficult for me, because I would personally not have reacted the same way in a similar situation, but I also felt that I could convey that she thought it was a problem". A third addition concerned relationship to the user. It was clear that one interpreter at least reflected over knowing or not knowing the deaf user and the relationship to the user in the event, stating "I get influenced by her [i.e., the deaf user's] facial expressions, and I also feel I reflect them". Finally, under monitoring, the issue of handling cognitive load also came up, as the interpreters reported different strategies (interruption and clarification) for handling such a load.

When it comes to the categorization of strategies, one strategy that all but one interpreter mentioned was added, namely, clarification. Again, this category reflects the different type of event that dialogue interpreting is as compared to simultaneous conference interpreting. The SL interpreters in this context all use the simultaneous technique, but the fact that they participate in a three-party dialogue gives them the opportunity to ask for clarification of the utterance, which they also regularly do.

Finally, retrospections in this context were challenging in two regards. First, the experienced interpreters were all very limited in their retrospective comments, one of them to the point where she was completely silent throughout the whole cue, only adding two short comments afterwards. Second, many of the participants complained that the cue was not identical to the dialogue they had interpreted.

Table 1 shows reported processing problems and their categories. As can be seen from this table, the inexperienced interpreters reported more processing problems. And although simultaneity could be an issue in SLI, given that the interpreting technique is simultaneous (albeit in a dialogue), none of the participants report on problems with simultaneity.

\begin{tabular}{|c|c|c|c|c|c|c|}
\hline & $\begin{array}{c}\text { Diana } \\
(\exp )\end{array}$ & $\begin{array}{l}\text { Nina } \\
(\exp )\end{array}$ & $\begin{array}{l}\text { Tanja } \\
\text { (exp) }\end{array}$ & $\begin{array}{c}E v a \\
\text { (inexp) }\end{array}$ & $\begin{array}{l}\text { Nadja } \\
\text { (inexp) }\end{array}$ & $\begin{array}{l}\text { Gunnel } \\
\text { (inexp) }\end{array}$ \\
\hline \multicolumn{7}{|l|}{ Comprehension } \\
\hline Perception & & 2 & 1 & & 2 & 1 \\
\hline Lexical access in SL & & & 1 & 4 & 1 & 1 \\
\hline Syntactic processing & & & & 1 & & \\
\hline \multicolumn{7}{|l|}{ Text integration } \\
\hline Text comprehension & & & 1 & 4 & 2 & 4 \\
\hline \multicolumn{7}{|l|}{ Translation } \\
\hline TL retrieval & 1 & & 1 & & 2 & \\
\hline Equivalent & & & & & & \\
\hline \multicolumn{7}{|l|}{ Simultaneity of tasks } \\
\hline \multicolumn{7}{|l|}{ SL.TL } \\
\hline \multicolumn{7}{|l|}{ TL delays } \\
\hline & 1 & 2 & 4 & 9 & 7 & 6 \\
\hline
\end{tabular}

Table 1. Number of reported processing problems 
Table 2 shows the monitoring categories, with the new additions in bold. Most of the reports on monitoring are related to the new categories, but there is also some reporting on the interpreters' own mood and on issues of translation. Just as for previous studies with retrospection on simultaneous conference interpreters (Ivanova 1999; Tiselius 2013), monitoring is not necessarily something the participants report extensively on.

\begin{tabular}{|c|c|c|c|c|c|c|}
\hline & $\begin{array}{c}\text { Diana } \\
\text { (exp) }\end{array}$ & $\begin{array}{l}\text { Nina } \\
\text { (exp) }\end{array}$ & $\begin{array}{l}\text { Tanja } \\
\text { (exp) }\end{array}$ & $\begin{array}{l}\text { Eva } \\
\text { (inexp) }\end{array}$ & $\begin{array}{l}\text { Nadja } \\
\text { (inexp) }\end{array}$ & $\begin{array}{l}\text { Gunnel } \\
\text { (inexp) }\end{array}$ \\
\hline Translation & & & & & & 2 \\
\hline \multicolumn{7}{|l|}{ Inner speech } \\
\hline \multicolumn{7}{|l|}{ Time } \\
\hline \multicolumn{7}{|l|}{ Internal commentary } \\
\hline Mood & & & 1 & 2 & 2 & \\
\hline Conveying mood & & & & 1 & & 1 \\
\hline Handling turns & 3 & & & & & 4 \\
\hline Relationship to user & 2 & & & & & \\
\hline $\begin{array}{l}\text { Handling cognitive } \\
\text { load }\end{array}$ & & & & & 1 & \\
\hline Total & 5 & - & 1 & 3 & 3 & 7 \\
\hline
\end{tabular}

Table 2. Number of reported instances of monitoring. Categories added to Ivanova's original in bold

In table 3, on the use of strategies, most of the reports for both the experienced and inexperienced interpreters concern demands for clarification, which is again a category that can be expected in this type of situation. The reports here are fairly evenly distributed among all the interpreters.

\begin{tabular}{|c|c|c|c|c|c|c|}
\hline Strategy code (SC/) & $\begin{array}{c}\text { Diana } \\
(\exp )\end{array}$ & $\begin{array}{l}\text { Nina } \\
\text { (exp) }\end{array}$ & $\begin{array}{l}\text { Tanja } \\
(\exp )\end{array}$ & $\begin{array}{c}\text { Eva } \\
\text { (inexp) }\end{array}$ & $\begin{array}{l}\text { Nadja } \\
\text { (inexp) }\end{array}$ & $\begin{array}{l}\text { Gunnel } \\
\text { (inexp) }\end{array}$ \\
\hline Clarification (C) & & 2 & 1 & 2 & 1 & 2 \\
\hline \multicolumn{7}{|l|}{ Selection (S) } \\
\hline \multicolumn{7}{|l|}{ Summarization (Sum) } \\
\hline \multicolumn{7}{|l|}{ Restructuring (Rest) } \\
\hline Creative interpretation $(\mathrm{Cr})$ & & & 1 & & & \\
\hline Overgeneralization (Overgen) & & & & 1 & 2 & \\
\hline \multicolumn{7}{|l|}{ Deletion (D) } \\
\hline \multicolumn{7}{|l|}{ Explication (Expl) } \\
\hline \multicolumn{7}{|l|}{ Compromise (Acc) } \\
\hline Total & & 2 & 2 & 3 & 3 & 2 \\
\hline
\end{tabular}

Table 3. Number of reported strategies

Finally, when it comes to the use of macro strategies ${ }^{3}$, only one of the interpreters talked about a macro strategy, viz. putting herself in the right mindset (career counseling) before starting to interpret (i.e., pre-activation of relevant domain knowledge).

3 Macro strategy categories identified by Ivanova (1999) and Englund Dimitrova/Tiselius (2009) are: knowledge about the speaker; pre-activation of relevant domain language; general characteristics of the SL text; use of general interpreting/translating technique; use of interpreting/translating aids. 


\subsection{Observations from the product data and from the dialogues}

When it comes to the actual interpreting acts, there are some general differences between the experienced and inexperienced interpreters. As stated above, the dialogue varied in length more among the three experienced interpreters, whereas the students had almost exactly the same length. One can only speculate about the reasons for this, but one possibility could be that the dialogue was more participant-driven for the inexperienced interpreters, and more interpreter-driven for the experienced interpreters, meaning that the dialogue could vary more as the participants did not have to rely as much on their script with the experienced interpreters. Although dialogues varied, they did not vary to the extent that comparisons could not be made.

\subsubsection{Processing time}

In a BA thesis on this material, Lundberg (2016) found that the experienced interpreters had a longer processing time (or lag time) than inexperienced interpreters at both the beginning and the end, and both into and from sign language (see table 4). She also observed that the experienced interpreters seemed to be better at managing turn taking, as they were confident in keeping the turn until they had finished, whereas the inexperienced interpreters let go of the turn as soon as one of the participants indicated that they were ready to take over the turn, for example when the deaf participant lifted her hands or the hearing participant made a sound. Yet both the experienced and the inexperienced interpreters commented in the retrospective interviews on the difficulties they encountered in turn taking.

$\begin{array}{lllll}\text { Interpreters } & \begin{array}{l}\text { Processing time at } \\ \text { the beginning when } \\ \text { interpreting into SSL } \\ \text { (in seconds) }\end{array} & \begin{array}{l}\text { Processing time } \\ \text { at the end when } \\ \text { interpreting into } \\ \text { SSL (in seconds) }\end{array} & \begin{array}{l}\text { Processing time at } \\ \text { the beginning when } \\ \text { interpreting into } \\ \text { spoken Swedish (in } \\ \text { seconds) }\end{array} & \begin{array}{l}\text { Processing time at the } \\ \text { end when interpreting }\end{array} \\ \text { (in seconds) }\end{array}$

Table 4. Processing time (in seconds) when interpreting into Swedish Sign Language (SSL) and into spoken Swedish

\subsubsection{Terminology}

The data shows that inexperienced interpreters struggle much more with terminology than experienced interpreters do, both into Swedish Sign Language and into Swedish. In this study, the experienced interpreters came across new terminology both in Swedish Sign Language and in Swedish, but they seemed to immediately internalize and use it. The deaf participant was feeding the interpreters with terminology: for instance, the plot in the role-play stated that the deaf participant was trained as an archivist and was now looking for that type of job. In this context, 'archivist' was perhaps not the most expected term for any of the participants, neither in Swedish Sign Language nor in Swedish spoken language, and it also has a hand shape which in Swedish Sign Language also could mean 'storeman'. The deaf participant showed the sign and fingerspelled it to the interpreters when it came up, anticipating that this would be an unusual term. The experienced interpreters used the term in their interpreting either immediately or after asking for clarification, whereas the inexperienced interpreters either used paraphrasing (both in spoken Swedish and Swedish Sign Language), stumbled on the word in Swedish spoken language (corresponding to non-standard English 'archivian', 'archivaian', and so forth), or used incorrect signs in Swedish Sign Language (e.g., 'layer' as an unsuccessful association of 'store', two terms whose signs in Swedish Sign Language resemble each other). 'Archivist' was the most prominent example of 
terminology difficulties, but the inexperienced interpreters struggled surprisingly often with terminology, especially considering that they were given information materials with the terminology one week beforehand. The reasons for this, other than the obvious issue of the lack of preparation, may also be that they are still beginners in sign language (having learned it only for one year before the interpreting program). However, the inexperienced participant with Swedish Sign Language as her L1 seemed to struggle just as much with the terminology.

\subsubsection{Transfer of mood}

After the role-plays, the deaf participant spontaneously commented that she felt that it was more difficult to convey her frustration and disappointment through the more inexperienced interpreters. It is also clear from the recordings that the experienced interpreters seem both more insistent in their interpreting, while faithfully expressing the deaf participant's highly repetitive dissatisfaction, and more exact in rendering the deaf participant's tone. Admittedly, these are impressions that are difficult to measure.

\subsubsection{Support from the deaf participant}

Another impression deals with the deaf participant's participation in the conversation. The deaf participant seems to take more responsibility for the dialogue when the interpreter is inexperienced. When an inexperienced interpreter is working, the deaf participant is more active in taking the turn, both signaling for turn taking and touching the hearing participant for attention. Furthermore, the deaf participant feeds the inexperienced interpreters much more with terminology and uses fingerspelling more. The deaf participant also repeats her utterances more often when the interpreter is inexperienced. Although these strategies probably serve as support to the interpreters, they may also reflect the deaf participant's fear of not being correctly interpreted. Another variable here is the fact that the deaf participant had no problem identifying the inexperienced interpreter in this event. Apart from their fluency in sign language, they were younger and not part of the usual corps of SL interpreters. As the Swedish Sign Language and deaf community are small, the persons involved either know or at least know of each other in many cases. It is therefore difficult to know whether the deaf participant unconsciously took the role as a teacher for these inexperienced interpreters or if it would be a natural behavior for any deaf person encountering a less skillful interpreter.

\section{Discussion}

The study reported in this article compared the performance of experienced and inexperienced Swedish Sign Language interpreters in an interpreted dialogue from a process perspective, with the aim of investigating reported or observed differences. The study also investigated whether methods previously used to investigate the interpreting process in simultaneous conference interpreting - namely, retrospection, identification, and the classification of processing problems, monitoring, and strategy use - were applicable to SLI in a dialogue setting.

We can conclude that there are both reported and observed differences when it comes to the interpreting process between the experienced and inexperienced Swedish SL interpreters who participated in this study. The differences are present in the reported processing problems (with experienced interpreters reporting fewer such problems), the reported instances and types of monitoring (though with neither group reporting many such instances; see Englund Dimitrova/Tiselius 2009 and Tiselius 2013), and in the product data (with experienced interpreters having longer processing times). ${ }^{4}$ There are however less differences in the reported use of strategies to solve processing problems, with both groups reporting very few strategies - this may be because processes

4 Though the processing times were considerably shorter than for instance Cokely (1986) found, this difference may perhaps be found in the context, as Cokely investigated lectures and not dialogues. 
are already automatized and therefore not explicitly mentioned, or because of a lack of discourse to talk about strategies.

The cue used for retrospection turned out less smooth than expected. Cues for this type of retrospection can be the participants' own interpreted event, the manuscript for the role-play (if such a manuscript exists), or, as in this case, a prerecorded version of the role-play but without the interpreter. Participants commented that this was not exactly the same as what happened in their role-play. One of the reasons for not using the participants' own interpreted event is the high risk (reported in Englund Dimitrova/Tiselius 2009) of participants explaining and excusing what they did based on what they see in the recording rather than recalling their activities, choices, and decisions.

One of the student participants reported that they did not use the preparation material, and only one participant talked about putting herself in the right mindset. These types of macro-strategies are normally part of any trained interpreter's professional practice. Yet we cannot assume that they are so conscious that they are reported in a retrospective interview, as they may very well be automatized processes.

There are limitations of this study stemming from the small population investigated $(n=6)$. It could also be argued that since the data was elicited and not natural it may give a skewed idea of the interpreted event, although natural data may not have been comparable between the participants in the same way. Finally, the researcher's lack of sign language knowledge may constitute a limitation; to remedy this, the data was partly analyzed together with hearing signers.

\section{Concluding remarks}

Although the material is based on such a small sample that no general conclusions can be drawn, it gives indications that need to be investigated further. When it comes to the instruments used for investigating the interpreting process, it is clear that they need to be adapted to the dialogue setting, although the instruments do seem to be appropriate for the analysis of both spoken language and sign language interpreting. Since, the instruments seem appropriate for both types of interpreting it could support the assumption of similarities in cognitive aspects of dialogue interpreting in the two types.

The fact that the data showed differences of both process and products between experienced and inexperienced interpreter participants in dialogue interpreting of sign language lends support to previous studies that interpreting experience and with that, stronger professional self-concept influence the interpreting performance.

Future studies will have to include more participants. The cue for retrospection also needs to be further developed. These are challenges that need to be met in future studies.

\section{References}

Andres, Dörte 2011: Ein integrativ konzipiertes Dolmetschprozessmodell. In Studia Universitatis Babes-Bolyai Philologia 1, 81-103.

Bonini, Francesca/Burle, Boris/Liégeois-Chauvel, Cathrine/Régis, Jean/Chauvel, Patrick/Vidal, Franck 2014: Action Monitoring and Medial Frontal Cortex: Leading Role of Supplementary Motor Area. In Science 343:6173, 888-891.

Bontempo, Karen/Napier, Jemina 2014: Evaluating Emotional Stability as a Predictor of Interpreter Competence and Aptitude for Interpreting. In Pöchhacker, Franz/Liu, Minhua (eds.), Aptitude for Interpreting. Amsterdam/Philadelphia: John Benjamins, 87-106.

Cokely, Dennis 1992: Interpretation: A Sociolinguistic Model. Burtonsville, MD: Linstok Press.

Cokely, Dennis 1986: The Effects of Lag Time on Interpreter Errors. In Sign Language Studies 53, 341-375.

Colonomos, Betty 1997: Pedagogical Model of the Interpreting Process. College Park, MD: Bilingual Mediation Center.

Conrad, Patricia/Stegenga, Susan 2005: Case Studies in Education: Practical Application of Ethics and Role. In Janzen, Terry (ed.), Topics in Signed Language Interpreting. Amsterdam/Philadelphia: John Benjamins, 293-322. 
Corsellis, Ann 2008: Public Service Interpreting: The First Steps. New York: Palgrave Macmillan.

Corsellis, Ann/Vanden Bosch, Yolanda 2014: Testing Knowledge of the Legal Context. In Giambruno, Cynthia (ed.), Assessing Legal Interpreter Quality through Testing and Certification: The Qualitas Project. Alicante: Publicaciones Universidad de Alicante, 69-76 [online]. http://www.qualitas-project.eu/sites/qualitas-project.eu/files/the qualitas_project_web.pdf (accessed 15 August 2017).

Englund Dimitrova, Birgitta 1997: Degree of Interpreter Responsibility in the Interaction Process in Community Interpreting. In Carr, Silvana, E./Roberts, Roda/Dufour, Aideen/Steyn, Dini (eds.), The Critical Link: Interpreters in the Community. Amsterdam/Philadelphia: John Benjamins, 147-164.

Englund Dimitrova, Birgitta 1991: När två samtalar genom en tredje: Interaktion och icke-verbal kommunikation $i$ medicinska möten med tolk [When two parties speak through a third: Interaction and non-verbal communication in medical encounters with an interpreter]. Stockholm: Centrum för tvåspråkighetsforskning.

Englund Dimitrova, Birgitta/Tiselius, Elisabet 2016: Cognitive Aspects of Community Interpreting: Toward a Process Model. In Muñoz Martín, Ricardo (ed.), Reembedding Translation Process Research. Amsterdam/Philadelphia: John Benjamins, 195-214.

Englund Dimitrova, Birgitta/Tiselius, Elisabet 2014: Retrospection in Interpreting and Translation: Explaining the Process? In MonTI, Special Issue 1, 177-200.

Englund Dimitrova, Birgitta/Tiselius, Elisabet 2009: Exploring retrospection as a research method for studying the translation process and the interpreting process. In Alves, Fabio/Göpferich, Susanne/Mees, Inger (eds.), Methodology, Technology and Innovation in Translation Process Research. (Copenhagen Studies in Language 38), Copenhagen: Samfundslitteratur, 109-134.

Frishberg, Nancy 1990: Interpreting: An Introduction. Rockville, MD: RID Publications.

Gerver, David 1971: Aspects of Simultaneous Interpretation and Human Information Processing. Doctoral dissertation, Oxford University, UK.

Gile, Daniel 1985: Le modèle d'efforts et l'équilibre d'interprétation en interprétation simultanée [The model of effort and balance of interpretation in simultaneous interpreting]. In Meta 32:2, 164-169.

Grbić, Nadja/Pöllabauer, Sonja 2006: Community Interpreting: Signed or Spoken? Types, Modes, and Methods. In Linguistica Antverpiensia NS 5, 247-261.

Hale, Sandra 2007: Community Interpreting. Basingstoke: Palgrave Macmillan.

Hoza, Jack 2016: Interpreting in the Zone: How the Conscious and Unconscious Function in Interpretation. Washington, DC: Gallaudet University Press.

Hyltenstam, Kenneth 2016: Introduction: Perspectives on Advanced Second Language Proficiency. In Hyltenstam, Kenneth (ed.), Advanced Proficiency and Exceptional Ability in Second Languages. Boston/Berlin: Mouton de Gruyter, 1-14.

Ingram, Robert M. 1978: Sign Language Interpretation and General Theories of Language, Interpretation and Communication. In Gerver David/Siniako Wallace (eds.), Language Interpretation and Communication. New York: Plenum Press, 109-118.

Ivanova, Adelina V. 1999: Discourse Processing during Simultaneous Interpreting: An Expertise Approach. Doctoral dissertation. University of Cambridge, UK.

Kaczmarek, Łukasz 2010: Modelling Competence in Community Interpreting: Expectancies, Impressions and Implications for Accreditation. Doctoral dissertation. University of Manchester, UK [online]. https://www.escholar.manchester.ac.uk/item/?pid=uk-ac-man-scw:86535 (accessed August 15, 2017).

Köpke, Barbara/Nespoulous, Jean-Luc 2006: Working Memory Performance in Expert and Novice Interpreters. In Interpreting 8:1, 1-23.

Levelt, William. J. M. 1989: Speaking: From Intention to Articulation. Cambridge, MA: MIT Press.

Liu, Minhua 2009: How Do Experts Interpret? Implications from Research in Interpreting Studies and Cognitive Science. In Hansen, Gyde/Chesterman, Andrew/Gerzymisch-Arbogast, Heidrun (eds.), Efforts and Models in Interpreting and Translation Research: A Tribute to Daniel Gile. Amsterdam/Philadelphia: John Benjamins, 159-177.

Llewellyn-Jones, Peter 2013: Getting to the Core of Role: Defining Interpreters' Role-Space. In International Journal of Interpreting Edcation 5:2, 54-72.

Lundberg, Malin 2016: Lag Time: Skillnader mellan erfarna och oerfarna tolkar? [Lag time: Differences between experienced and inexperienced interpreters?]. Unpublished BA thesis, Stockholm University, Sweden [online]. http:// www.diva-portal.org/smash/get/diva2:967990/FULLTEXT01.pdf (accessed August 15, 2017).

Moser, Barbara 1978: Simultaneous Interpretation: A Hypothetical Model and its Practical Application. In Gerver, David/Siniako, Wallace (eds.), Language Interpretation and Communication. New York: Plenum Press, 353-368. 
Muñoz Martín, Ricardo 2014: Situating Translation Expertise: A Review with a Sketch of a Construct. In Schwieter, John/Ferreira, Aline (eds.), The Development of Translation Competence: Theories and Methodologies from Psycholinguistics and Cognitive Science. Newcastle upon Tyne: Cambridge Scholars Publishing, 2-54.

Nicodemus, Brenda/Emmorey, Karen 2013: Direction Asymmetries in Spoken and Signed Language Interpreting. In Bilingualism: Language and Cognition 16, 624-636.

Napier, Jemina 2015: Sign Language. In Pöchhacker, Franz (ed.), Routledge Encyclopedia of Interpreting Studies. London: Routledge, 376-381.

Napier, Jemina 2002: Sign Language Interpreting: Linguistic Coping Strategies. Coleford: Douglas McLean.

Roy, Cynthia B. 1993: A Sociolinguistic Analysis of the Interpreter's Role in Simultaneous Talk in Interpreted Interaction. In Multilingua 12:4, 341-363.

Schwenke, Tomina J./Ashby, Jeffrey S./Gnilka, Philip B. 2014: Sign Language Interpreters and Burnout: The Effects of Perfectionism, Perceived Stress, and Coping Resources. In Interpreting 16:2, 209-232.

Setton, Robin 1999: Simultaneous Interpretation: A Cognitive-Pragmatic Analysis. Amsterdam/Philadelphia: John Benjamins.

Skaaden, Hanne/Wadensjö, Cecilia 2014: Some Considerations on the Testing of Interpreting Skills. In Giambruno, Cynthia (ed.), Assessing Legal Interpreter Quality through Testing and Certification: The Qualitas Project. Alicante: Publicaciones Universidad de Alicante, 69-76 [online]. http://www.qualitas-project.eu/sites/qualitas-project. eu/files/the qualitas_project_web.pdf (accessed 15 August 2017).

Swabey, Laurie/Nicodemus, Brenda/Taylor, Marty M./Gile, Daniel 2016: Lexical Decisions and Related Cognitive Issues in Spoken and Signed Language Interpreting. In Interpreting 18:1, 34-56.

Tate, Granville/Turner, Graham 2002: The Code and The Culture: Sign Language Interpreters - In Search of the New Breed's Ethics. In Pöchhacker, Franz/Shlesinger, Miriam (eds.), The Interpreting Studies Reader. London: Routledge, 372-385.

Tiselius, Elisabet 2013: Experience and Expertise in Conference Interpreting: An Investigation of Swedish Conference Interpreters. Doctoral dissertation, University of Bergen, Norway [online]. http://bora.uib.no/bitstream/handle/1956/8747/dr-thesis-2013-Elisabet-Tiselius.pdf?sequence=1\&isAllowed=y (accessed 15 August 2017).

Timarová, Šarka 2012: Working Memory in Conference Simultaneous Interpreting. Doctoral dissertation, University of Leuven, Belgium/Charles University, the Czech Republic.

Toury, Gideon 1995: Descriptive Translation Studies and Beyond, Amsterdam/Philadelphia: John Benjamins.

Van Dijk, Rick/Christoffels, Ingrid/ Postma, Albert/ Hermans, Daan 2012: The Relation between the Working Memory Skills of Sign Language Interpreters and the Quality of Their Interpretations. In Bilingualism: Language and Cognition 15, 340-350.

Vik-Tuovinen, Gun-Viol 2006: Tolkning på olika nivår av professionalitet. [Interpreting on different levels of professionality]. Doctoral dissertation, University of Vasa, Finland.

Wadensjö, Cecilia 1998: Interpreting as Interaction. London/New York: Longmans.

Wilcox, Sherman/Shaeffer, Barbara 2005: Towards a Cognitive Model of Interpreting. In Janzen, Terry (ed.), Topics in Signed Language Interpreting: Theory and Practice. Amsterdam/Philadelphia: John Benjamins, 27-50.

Wehrmeyer, Ella 2015: Comprehension of Television News Signed Language Interpreters: A South African Perspective. In Interpreting 17:2, 195-225. 